\title{
Abkürzungen und Symbole
}

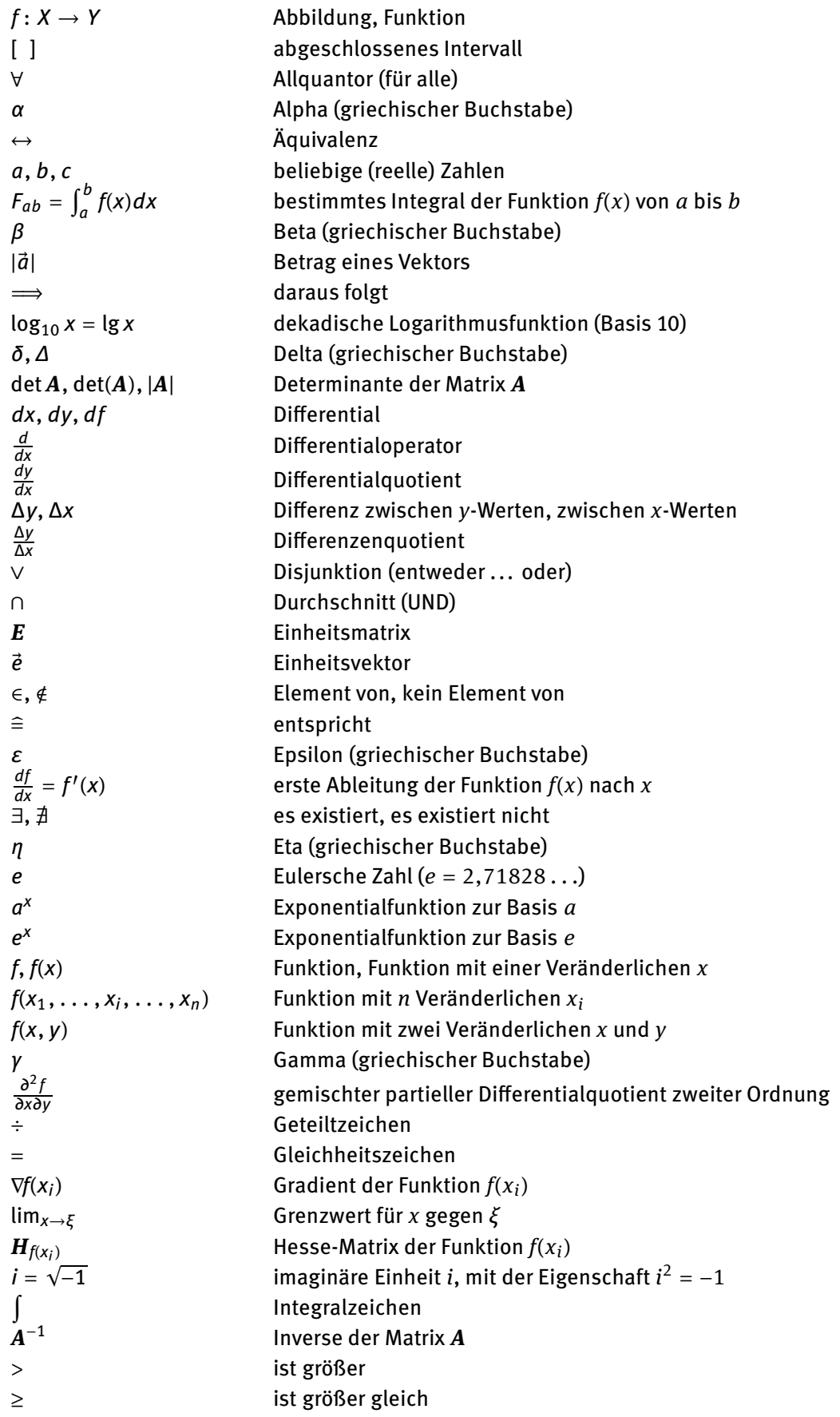




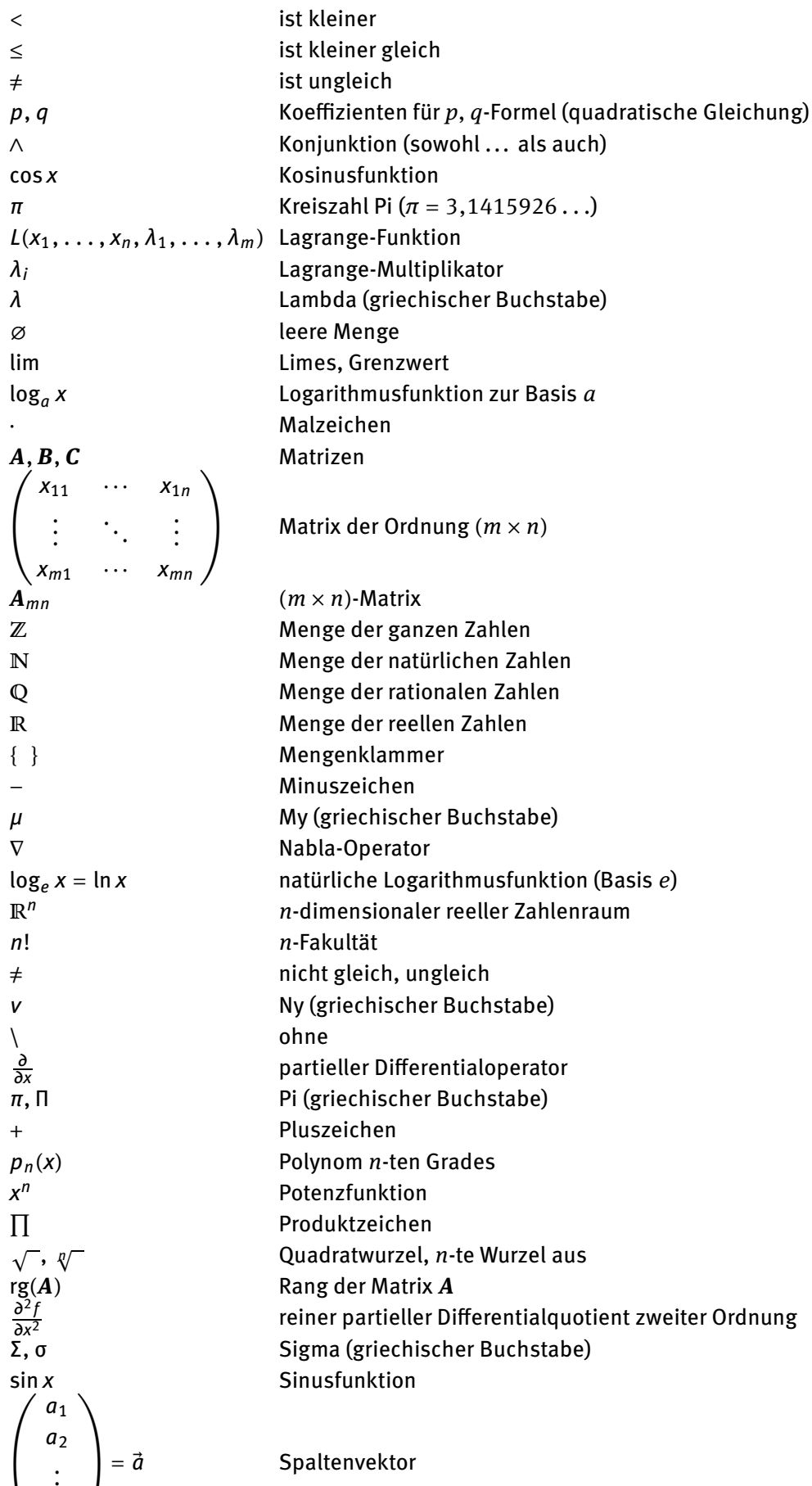




$\begin{array}{ll}F(x) & \text { Stammfunktion zu } f(x) \\ \sum & \text { Summenzeichen } \\ \subset & \text { Teilmenge von } \\ \boldsymbol{A}^{\top} & \text { Transponierte der Matrix } \boldsymbol{A} \\ \vec{a}^{\top} & \text { transponierter Vektor } \\ f^{-1}(x) & \text { Umkehrfunktion } \\ \int f(x) d x & \text { unbestimmtes Integral der Funktion } f(x) \\ \approx & \text { ungefähr gleich } \\ \infty & \text { unendlich } \\ x, y, z & \text { Variablen } \\ \cup & \text { Vereinigung (ODER) } \\ \xi & \text { Xi (griechischer Buchstabe) } \\ \left(a_{1}, a_{2}, \ldots, a_{n}\right)=\vec{a}^{\top} & \text { Zeilenvektor } \\ \frac{d^{2} f}{d x^{2}}=f^{\prime \prime}(x) & \text { zweite Ableitung der Funktion } f(x) \text { nach } x\end{array}$


